Printed in the Republic of Korea

1 ANALYTICAL SCIENCE

2 \& TECHNOLOGY

Vol. 27, No. 2, 108-113, 2014

http://dx.doi.org/10.5806/AST.2014.27.2.108

\title{
The study for VOCs analysis in long path by open path FT-IR spectrometer
}

\author{
Nam Wook Cho ${ }^{1}$, Won Bo $\mathrm{Cho}^{2, \star}$ and Hyo Jin $\mathrm{Kim}^{2}$
}

${ }^{1}$ Korea Institute of Construction Technology, 211 Deawha-Dong Ilsan-Gu Goyang-Si, Gyeonggi-Do 411-712, Korea

${ }^{2}$ College of Pharmacy, Dongduck Women's University 23-1Hawolgok-Dong, Seoul 136-714, Korea

(Received June 11, 2013; Revised December 26, 2013; Accepted February 24, 2014)

\section{Open path FT-IR spectrometer를 사용한 원거리의 $\mathrm{VOCs}$ 측정에 관한 연구}

\author{
조남욱 ${ }^{1} \cdot$ 조원보 ${ }^{2, \star} \cdot$ 김효진 $^{2}$ \\ 1한국건설기술연구원, ${ }^{2}$ 동덕여자대학교 약학과 \\ (2013. 6. 11. 접수, 2013. 12. 26. 수정, 2014. 2. 24. 승인)
}

\begin{abstract}
The harmful materials as volatile organic compounds $\left(\mathrm{VOC}_{\mathrm{S}}\right)$ that is easy for gas to be changed from liquid on ambient temperature, those should be controlled by Korea Chemicals Management Association. The VOCs samples should be collected directly in place so that those could be analyzed. Generally but it couldn't avoid to have the risk of analyst. Moreover, if there is the place limited to entrance, it is impossible to collect directly and measure. Owing to such problem, it tried to be solved by open path FT-IR spectrometer that could be studied on the combustion gases within long path and VOCs samples were tried to measure to large volume by remote and real time. Firstly, it was to investigate optimized measured length between the system and benzene sample of VOCs. As result, The optimized measured length was confirmed with 15 meter length and the qualitative analysis could be measured on seven VOC samples. The calibration curve as quantitative analysis of benzene samples could be worked. On the basis of the result, the system as remote monitor could show to have potentiality

요 약: 휘발성 유기 화합물(VOC)은 상온에서 가스 상태로 있거나 가스 상태가 되기 쉬운 화합물로써 유해화학물질관리법으로 관리되고 있는 유해물질이다. 이러한 휘발성 유기 화합물을 측정하기 위해서 일 반적으로 측정자가 직접 현장에서 포집하는 방법을 채택하고 있으나, 이 방법은 측정자가 위험에 노출될 수 있으며, 측정자의 접근이 제한적이거나 대공간일 경우 측정이 어려운 단점을 가진다. 특히 대공간에 서 포집하는 경우 샘플링에서 오는 오차 및 대공간에서 샘플링의 대표성을 확보하지 못하는 단점을 가 지며, 넓은 공간을 연속하여 실시간 측정이 불가능한 점도 간과할 수 없다. 이러한 문제점을 해결하기 위 하여 본 연구에서는, 주로 대기오염 등의 모니터링에 부분적으로 연구되어온 개방형적외선분광기(open path FT-IR spectrometer)를 사용하여 원거리에서 대용량, 실시간 측정을 시도하였다. 우선 VOCs 중 벤젠
\end{abstract}

Corresponding author

Phone : +82-(0)2-940-4525 Fax : +82-(0)2-940-4195

E-mail : chowonbo@naver.com 
을 대상으로, 시스템과 VOCs 시료와의 분석 최적거리를 측정하였으며, 확인 결과 15 meter에서 가장 좋 은 흡광강도(absorption intensity)를 확인하였다. 15 meter의 최적거리에서 휘발되는 7 종의 VOCs를 원거 리 정성분석하였으며, 벤젠을 대상으로 정량 분석을 시도하였다. 본 연구를 통해 기존에 분석방법으로 불 가능하였던 대공간 VOCs의 측정 및 상시 모니터링의 가능성을 확인할 수 있었다.

Key words: open path FT-IR spectrometer, monitoring of VOCs

\section{1. 서 론}

휘발성 유기 화합물(VOC)은 인체에 해로운 화합물 로써, 유해화학물질 관리법으로 규제되는 물질이다. 화합물은 특히 장기적으로 노출될 경우 인체에 유해 하기 때문에 휘발성 유기 화합물을 많이 취급하는 산 업체 등에서 관리에 유의하여야 한다. 이러한 휘발성 유기 화합물을 작업 현장에서 분석할 때, 일반적으로 시료 포집법을 사용하여 대기 중 가스를 포집 한 뒤에 분석적으로 가스 크로마토그래피(gas chromatography) 를 사용하여 측정하게 된다. ${ }^{1}$ 시료 포집은 주로 대공 간에서 일정 시간동안 펌프를 통하여 대기 중 가스를 포집하는 방식인데, 대공간 중의 일정한 영역을 대상 으로 포집하기 때문에 시료의 대표성을 확보하는데 한계가 있다. 따라서 여러지점을 측정하여 VOCs를 실시간적으로 모니터링하기 위해서는 분광 분석 법이 일반적으로 적합하나 기존의 적외선 분광 분석기의 경우에는 실험실에서 측정하는 방식이기 때문에, 가스 를 포집 하는 경우에 있어서는 크로마토그래피 측정 방법과 동일한 방법을 채택하고 있다. 저자들은 최근 에 적외선 방법 중에서 원거리 측정 방법으로 사용하 여 원거리에서 유기물을 측정할 수 있는 원거리용 중 적외선 분석 장비인 개방형 푸리에 변환 분광기(open path FT-IR spectrometer) ${ }^{2}$ 를 사용하여 실시간적으로 측정하였다. 이 방법은 원거리의 측정에 적합한 원거 리 대구경 렌즈를 사용하여 중적외선 분석할 때 사용 되는 데, 주로 화산 등에서 발생하는 연소 가스 분석 에 주로 사용되고 있으며, 최근에는 그 측정 분야가 더 넓어지고 있다. ${ }^{3,4}$ 이 분광기는 측정해야 하는 장소 에 직접 가서 샘플링 채취 등을 하지 않기 때문에 위 험한 측정 장소에서 사용하기에는 가장 적합한 분석 장비라고 할 수 있다. 본 연구에서는 이러한 장점을 가진 분광기를 사용하여 대표적인 $\mathrm{VOCs}$ 시료 중 8 종 에 대하여 대기 중의 원거리에서 정성 분석을 하였다. 정성 분석 결과는 대기에 대한 간섭 현상5이 있음에도 불구하고 정성 분석이 가능 한 것을 확인 할 수 있었
으며, 특히 벤젠은 추가적으로 정량 분석까지 하였다. 대기 중 많은 가스에 대한 간섭(interference) 현상을 최소화 ${ }^{6}$ 하기 위하여 계량 분석 화학(chemometrics)을 기반으로 한 PLSR (partial least square regression) 정 량 분석 방법을 사용하였으며, 그 결과 원거리에서 VOCs의 실시간 측정이 가능한 것을 확인하였다.

\section{2. 실 험}

\section{1. 표준 시료 및 시료 증기화 부분 구성}

휘발성 유기화합물을 측정하기 위하여 휘발성 유기 화합물인 벤젠(benzene) 등 7 종 시료(benzene, cyclohaxane, dimethyl amine, n-haxane, ethyl methyl ketone, methanol, isopropyl alcohol)를 대상으로 하였다. 액체 상태의 시약을 휘발시키기 위하여 중탕기(bath, Korea) 를 사용하였다. 휘발된 유기 화합물을 일정하게 측정 거리를 유지하도록 하기 위하여 중탕기 위 부분에서 일정한 속도로 VOCs가 배출될 수 있는 환기구 (ventilation, Korea)를 구성하였다.

\section{2. 측정 방법}

휘발성 유기 화합물을 측정하기 위하여 본 연구에 서는 개방형 푸리에 변환 분광 분석기를 사용하였으 며 측정장비는 2 개의 부분으로 구성된다. 하나는 $\mathrm{q}$ 분 광기부분의 푸리에 변환 간섭계(FT-interferometer)로써 수평이 아닌 수직형(vertical)으로 구성되어 있다. ${ }^{7.8}$ 그 리고 입사광 앞에는 대구경 (F-number $>2,100 \mathrm{~mm}$ ) 렌즈가 부착되어 있어 보다 넓은 면적을 측정할 수 있어 많은 양의 가스를 측정할 수 있다. 또한 중적외 선 광원으로써 Globar 램프와 이 램프의 광이 확산되 지 아니하고 원거리를 주사하기 위하여 대형 반사경 (diameter:500 mm, material: gold)을 사용하였다. 전체 측정 구조는 Fig. 1과 같다. 측정 방법은 중적외선 광 원과 분광기를 $15 \mathrm{~m}$ 전후로 이격하고, 적외선광원과 분광기사이에 중탕기 및 환기구를 설치하였다. 중탕기 내에 급격한 시료의 휘발을 방지하기 위하여 bath의

Vol. 27, No. 2, 2014 


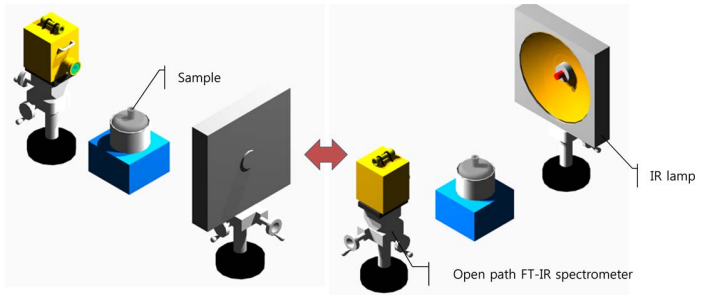

Fig. 1. Schematic diagram for measurement of open path FTIR spectrometer.

하단 부분에 열을 가열하도록 하였으며, 증발되어 나 오는 출구의 면적을 협소하게 하여 일정한 밀도를 유 지하였다. 일정한 밀도를 유지하면서 발생되는 VOCs 기체를 환기구를 통하여 배출하고 지속적으로 균질한 증기화가 될 수 있도록 구성하여 외부의 환경영향이 최소화되도록 하였다. 적외선 광원과 분광기를 중탕기 로부터 발생된 VOCs 기체 바로 위에 정렬하여 외부 확산으로 인한 오차를 최소화하였다. 탕기의 위치는 광원과 분광기의 전체 설치 거리의 중앙에 위치하게 하였다. 측정 방법은 시료를 휘발하기 전에 기준 신호 (Reference)를 측정하고, 기준 신호를 측정한 후 중탕 기를 $60{ }^{\circ} \mathrm{C}$ 로 가열하여 유기용제의 휘발을 측정한다. 유기용제는 각각 $60 \mathrm{~g}$ 을 사용하였으며, 측정 시간은 모두 증발될 수 있도록 10 분간 측정하였다. 이때 분광 기의 측정 조건은 700 부터 $4500 \mathrm{~cm}^{-1}$ 이며, 분해능 (Resolution)은 $0.5 \mathrm{~cm}^{-1}$ 로 하였다.

\section{3. 결과 및 고찰}

\section{1. 벤젠을 사용한 open path FT-IR 분광기의} 측정 거리에 대한 최적 조건

벤젠을 사용하여 중적외선 광원과 분광기의 최적의 측정 거리를 확인하기 위해 $10,15,20$ meter의 3 가지 경우로 측정하였다. 시료를 측정하기 전 우선 대기 중 기준스펙트럼을 측정하였으며, Fig. 2는 기준 스펙트 럼으로써 대기를 측정하기 때문에 1000 부터 2000 $\mathrm{cm}^{-1}$ 사이와 3000 부터 $4500 \mathrm{~cm}^{-1}$ 사이의 $\mathrm{OH}$ band가 주로 확인되었으며, $2400 \mathrm{~cm}^{-1}$ 에서는 $\mathrm{CO}_{2}$ band를 확 인할 수 있었다. 대기 중에는 $\mathrm{OH}$ 와 $\mathrm{CO}_{2}$ 의 스펙트럼 이 존재하며 따라서 기준 스펙트럼에서도 확인할 수 있다. 기준 스펙트럼을 측정하고 벤젠 시료를 휘발시 키면서 분광기와 시료까지의 거리를 $10,15,20$ meter 로 하여 각각 측정하였다. 분광기와 시료사이의 거리 가 $10,15,20$ meter이면 광원까지는 그 두 배의 거리

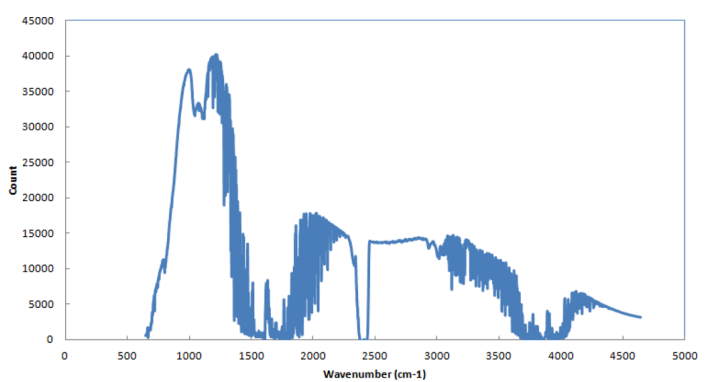

Fig. 2. Full spectra of reference at atmosphere.
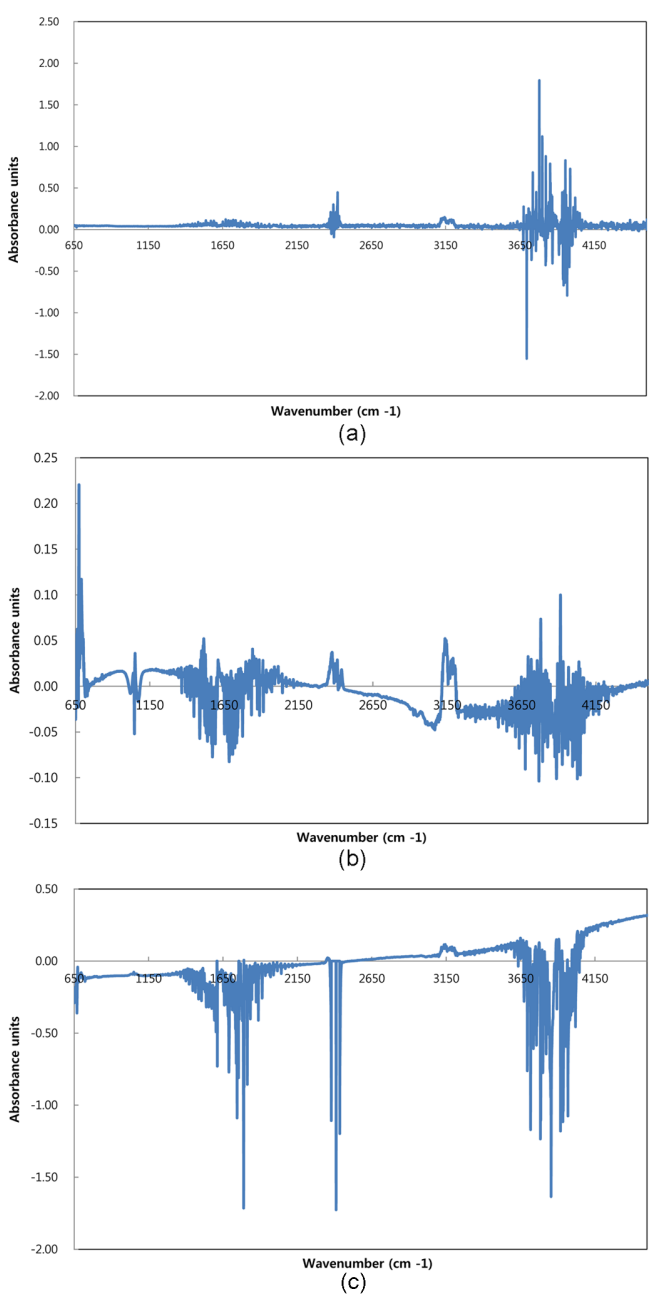

Fig. 3. Full absorbance spectra of benzene on pathlengthvariable. (a) 10 meter, (b) 15 meter, (c) 20 meter.

가 된다. Fig. 3은 각 거리에 따른 벤젠에 대한 전체 영역의 흡수스펙트럼이다. 흡수 스펙트럼은 벤젠이외 에 적외선 광원에 의해서 $\mathrm{OH}$ band와 $\mathrm{CO}_{2}$ band가 더 
활성화되어서 상대적으로 큰 흡광도를 가지는 것으로 측정되었다. 이는 벤젠을 증발시키는 온도에 의해서 기준 스펙트럼보다 높은 흡광도를 보인다. Fig. 3(a)는 10 meter일 때 벤젠의 흡수 스펙트럼이다. 10 meter일 때는 바탕선 흡수 스펙트럼의 흡광도가 가장 안정화 되어 있는 것으로 확인되었다. 하지만 $\mathrm{OH}$ band와 $\mathrm{CO}_{2}$ band의 흡수 스펙트럼이 큰 흡광도를 가지는 데 반해, 상대적으로 벤젠의 흡수 스펙트럼인 3100에서 $3200 \mathrm{~cm}^{-1}$ 는 매우 낮은 흡광도를 가지는 것으로 확인 되었다. ${ }^{9}$ Fig. 3(b)는 15 meter의 벤젠 흡수 스펙트럼 으로 10 meter에 비해서는 두 가지 흡수 스펙트럼의 흡광도가 상대적으로 낮은 것으로 확인되었으며, 벤젠 의 흡광도는 전체 스펙트럼의 흡광도에 비해서 상대 적으로 높은 것으로 확인되었다. 하지만 바탕 흡수 스 펙트럼 중에서 벤젠 흡수 스펙트럼이 바로 근처 스펙

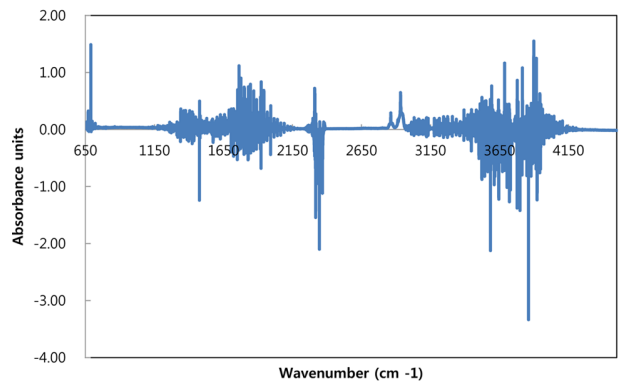

(a)

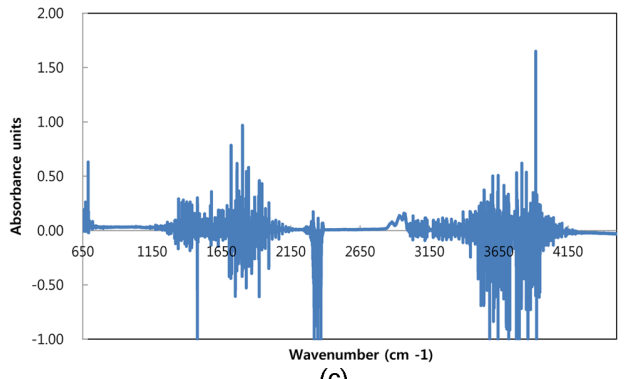

(c)

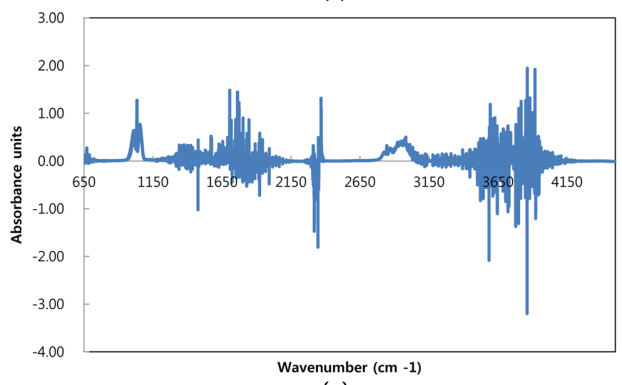

(e)
트럼인 $3000 \mathrm{~cm}^{-1}$ 에서는 $-\mathrm{AU}$ 를 가지기 때문에 10 meter에 비해 더 높은 흡광도를 가지는 것으로 확인되 었다. Fig. 3(c)의 경우 20 meter에서 벤젠 흡수스펙트 럼으로 두 가지 주요 흡수 스펙트럼이 $-\mathrm{AU}$ 값의 흡광 도로 측정되었다. 3 가지 조건에서는 15 meter에 가장 높은 벤젠의 흡광도를 가지는 것으로 측정되어 최적 의 측정 거리는 15 meter로 확인되었다. 이러한 결과 를 토대로 15 meter에서 추가적으로 7 종에 대한 흡수 스펙트럼을 측정하여 정성적으로 분리가 가능한 지 실험하였다.

\section{2. 벤젠이외에 6 종 VOCs의 흡수 스펙트럼}

벤젠 이외에 총 6 종 $\mathrm{VOCs}$ 에 대해서 최적 거리 조 건인 15 meter 측정 거리에서 측정하였다. Fig. 4는 총 6 종에 대한 $\mathrm{VOCs}$ 에 대한 흡수 스펙트럼 이다. 6

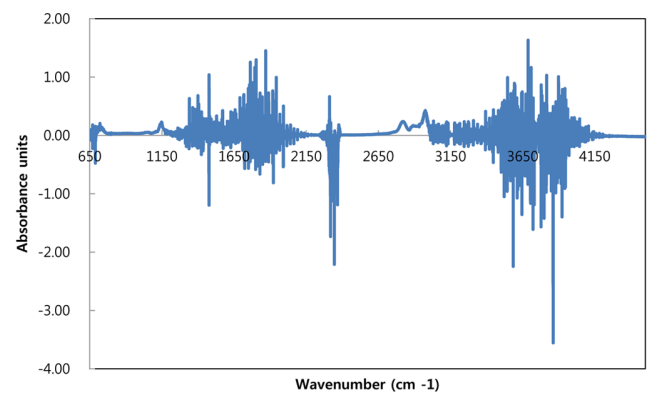

(b)

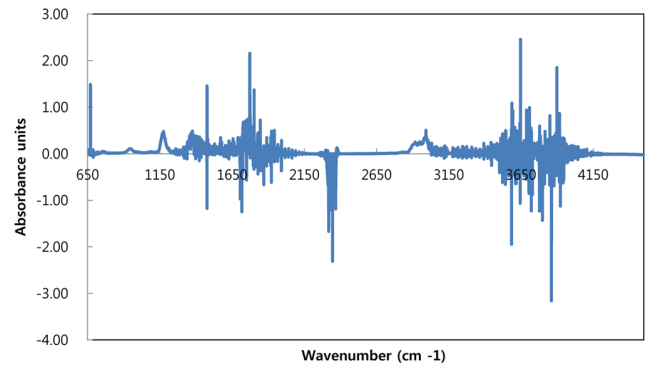

(d)

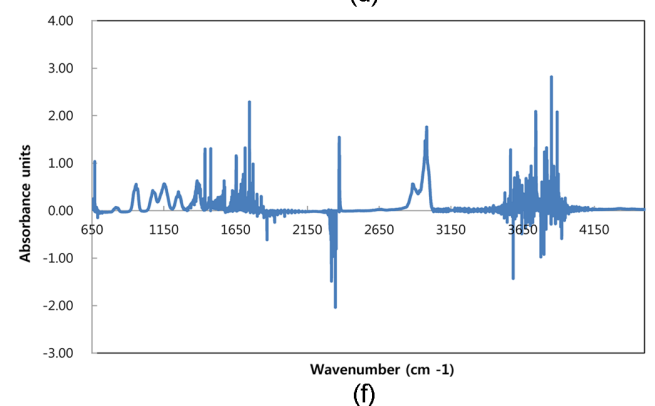

(f)

Fig. 4. Full absorbance spectra of six VOCs on 15 meter. (a) Cyclohaxane, (b) Dimethylamine, (c) N-haxane (d) Ethyl methyl ketone, (e) Methanol, (f) Isopropyl alcohol. 
가지의 $\mathrm{VOCs}$ 의 전체 스펙트럼은 벤젠의 전체 흡수 스펙트럼과 마찬가지로 대기 중에서 측정하여 $\mathrm{OH}$ 와 $\mathrm{CO}_{2}$ band의 흡수 스펙트럼의 흡광도가 높게 나타나는 것으로 측정되었다. 전체 6 종 $\mathrm{VOCs}$ 는 주로 $2700^{-1}$ 부 터 $3100 \mathrm{~cm}^{-1}$ 과 $900^{-1}$ 부터 $1300 \mathrm{~cm}^{-1}$ 에서 대부분 스 펙트럼이 확인 ${ }^{10}$ 되어 대기 중 주요 성분에 의한 스펙 트럼 간섭(interference)현상이 거의 없는 것으로 볼 수 있다. 그리고 6 종 VOCs 중에서 isopropyl alcohol는 $2700^{-1}$ 부터 $3100 \mathrm{~cm}^{-1}$ 에서 흡광도가 $1.8 \mathrm{AU}$ 로써 가장 높은 흡광도로 측정 되었다. n-hexane의 경우 흡수 스 펙트럼이 나머지 5 종 $\mathrm{VOCs}$ 에 비해서 가장 낮은 흡 광도로써 $0.15 \mathrm{AU}$ 로 확인되었으며, 이 성분의 흡수 스펙트럼도 거의 $2700^{-1}$ 부터 $3100 \mathrm{~cm}^{-1}$ 사이에서만 흡 수되고 다른 파수 대역에서는 흡수 스펙트럼이 확인 되지 않았다. 이러한 총 $6 \mathrm{VOCs}$ 의 흡수 스펙트럼의 특징 중 하나는 $\mathrm{O}-\mathrm{H}$ band 영역에서 대기 중 $\mathrm{O}-\mathrm{H}$ band에 의한 간섭현상이 거의 없다는 것이고, 이는 대 기 중 주요 성분 중 $\mathrm{H}_{2} \mathrm{O}$ 가 이미 기준 스펙트럼에서 측정되어 제거되었기 때문이다. 따라서 alcohol에서 $\mathrm{O}-\mathrm{H}$ band와 분리가 가능하여 $\mathrm{VOC}$ 측정의 흡수 스펙 트럼에서 보면 대기 중 $\mathrm{H}_{2} \mathrm{O}$ 와는 분리되어 측정 된다. 이러한 특징을 가지기 때문에 대기 중에서 직접 VOCs 를 측정하여도 대기 중 주요 성분에 의한 흡수 스펙트 럼에 의한 간섭 현상이 없다. 따라서 대기 중 직접 측 정하여도 $\mathrm{VOCs}$ 의 정성 분석이 가능한 것으로 확인되 었다.

\section{3. 벤젠의 다중 회귀곡선에 의한 정량 분석}

총 6 종 VOCs 중에서 benzene을 통한 정량 분석을 하여 대기 중에서 정량 분석이 가능 한지 확인하였다. 용질인 benzene을 n-hexane 용매의 혼합 비율을 5:5, 4:6, $1: 9$ 로 한 후 $60 \mathrm{~g}$ 씩 분취하여 bath 용기에 넣은 후 휘발 된 증기를 측정하였다. Open path FT-IR spectrometer의

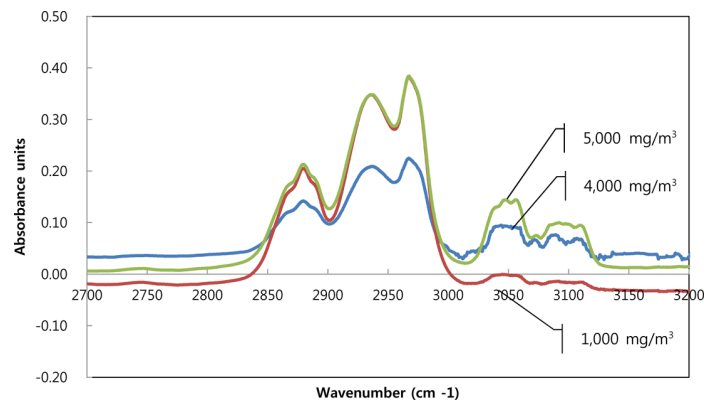

Fig. 5. Benzene spectra on concentrations.
Table 1. B-coefficients and intercept for prediction on four wavenumber selected of MLR

\begin{tabular}{lcccc}
\hline \hline & $3037 \mathrm{~cm}^{-1}$ & $3046 \mathrm{~cm}^{-1}$ & $3056 \mathrm{~cm}^{-1}$ & $3100 \mathrm{~cm}^{-1}$ \\
\hline B-coefficients & 6144 & -31820 & 42980 & 7714 \\
Intercept & \multicolumn{4}{c}{1945} \\
\hline
\end{tabular}

측정 면적에 대한 평균 농도(averaged concentration, $\left.\mathrm{g} / \mathrm{m}^{3}\right)$ 인 $5,000,4,000,1,000 \mathrm{mg} / \mathrm{m}^{3}$ 으로 측정 한 후 정 량 분석을 수행하였다. 3 가지 농도에 대한 정량 분석 방법은 다중 회귀곡선(MLR, Multiple linearity regression)을 사용하여 검정곡선 작업을 수행하였으며, 이때 사용한 소프트웨어는 Unscramber (Camo, USA) 이다. Fig. 5는 3 가지 농도의 benzene의 흡수 스펙트 럼으로써 benzene 농도에 따른 흡수 스펙트럼의 흡광 도가 선형적으로 감소되며, 2,900 부터 $3,000 \mathrm{~cm}^{-1}$ 사이 에 n-hexane과는 정성적으로 분리되기 때문에 benzene 의 흡수 스펙트럼에 간섭현상이 없는 것으로 보인다. 이 benzene의 흡수 스펙트럼 중에서 MLR을 위하여 $3037,3046,3056,3100 \mathrm{~cm}^{-1}$ 에 4 가지 파수 대역을 선택한 후 정량 분석을 실시하였다. 총 4 가지 파수 대역을 MLR로 정량 분석하면 Table 1과 같이 4 가지 파수대역에 의한 MLR 예측 식으로써 각 파수 별 Bcoefficients와 전체 예측 식의 intercept 값으로 계산되 었고, 이 때의 상관 관계로써, 선형계수 $\left(\mathrm{R}^{2}\right)$ 가 0.99 이 며, SEC (standard error of calibration)는 0.000568 를 가지는 것으로 확인 되었다. 따라서 open path FT-IR 분광기를 사용하여 원거리의 $\mathrm{VOCs}$ 에 대한 정성 및 정량 분석이 가능함을 입증하였다.

\section{4. 결 론}

본 연구에서는 연소 가스 및 일반 가스 분석에 주 로 사용되는 open-path FT IR spectrometer를 사용하 여 상온에서는 액체지만 휘발성이 높은 원거리의 VOCs (휘발성 유기 화합물)에 대한 정성 및 정량 분 석을 하였다. Benzene을 포함한 총 7 종 $\mathrm{VOCs}$ 에 대 한 대기 중 정성 분석을 위하여 bath에서 휘발 시키면 서 7 종 $\mathrm{VOCs}$ 의 흡수 스펙트럼으로 정성 분석이 가 능하였으며, benzene을 n-hexane에 희석한 후 평균 농 도를 계산하여 3 가지의 각 농도별 benzene의 흡수 스 펙트럼으로 정량 분석을 시도하였다. Benzene의 흡수 스펙트럼에서 4 가지 파수 대역만 선정 한 후 MLR을 사용하여 정량 분석을 하였으며, 그 결과 $\left(\mathrm{R}^{2}\right)$ 가 0.99 
로 좋은 선형성을 가지는 것으로 확인되었다. Openpath FT IR 분광기를 사용하여 일반 가스, 연소가스 및 VOCs에 대해 이로써, 정성 및 정량분석을 통한 모 니터링이 가능함을 입증하였다.

\section{Reference}

1. K. S. Na and Y. P. Kim, J. KAPRA, 14(5), 507-518 (1998).

2. W. F. Herget and J. D. Brasher, Opt. Eng., 19, 508-514 (1980).

3. D. F. Flanigan, Applied Optics, 25, 4253 (1986).
4. M. Hilton, A. H. Lettington and I. M. Mills, SPIE, 2089, 314-315 (1993).

5. D. Hong and S. Cho, Appl Spectrosc, 57, 299-308 (2003).

6. U. Müller and H. M. Heise, Field Anal Chem Technol, 3, 141-159 (1999).

7. D. W. Griffith, Appl. Spectr., 50, 59-70 (1996).

8. D. F. Flanigan, Applied Optics, 35, 6090-6098 (1996).

9. W. Chen, J. Burie and D. Boucher, Spectrochim. Acta A, 55, 2057-2075 (1999).

10. M. T. Gaudex, Pitsch, Analyst, 119, 665 (1994). 